\title{
Place of DNA in the identification of mutilated dead bodies
}

\author{
Gunethilake $\mathrm{KMTB}^{1}$, Vidanapathirana $\mathrm{M}^{2}$, Rahuman $\mathrm{MMA}^{1}$ \\ ${ }^{1}$ Teaching Hospital, Batticaloa, \\ ${ }^{2}$ Department of Forensic Medicine, Faculty of Medicine, University of Sri Jayewardenepura \\ *Corresponding author: Tel: 0094-718244641. E-mail address: mudithavidana@yahoo.co.uk
}

MLJSL. Vol 2. No 2. September. pp 50-53

\begin{abstract}
Introduction

DNA profiling is one of the most reliable methods of identification. But there are disadvantages such as high cost, and necessity of comparative samples. It is a vital method in situations with high profile cases or the necessity to prove beyond reasonable doubt in the court of law.
\end{abstract}

\section{Case report}

Several people died following a blast in or around an armory of a police station. After the initial scene investigation, 23 bodies were dispatched to the nearest tertiary care hospital along with two bags of body parts.

Those 23 bodies were recognized by facial features. The other two bodies were differentiated by using following features. According to the history, one officer had been bald headed with hair on his ears. The other one had been fair in complexion. At the autopsy, in one bag, there were pieces of an index finger, the pieces showed baldness and hair on the ears. In the second bag, a full hand was found. In both these cases finger prints were used for confirmation. Later, DNA testing re-confirmed the identifications.

\section{Conclusions}

Twenty three identified bodies were released soon due to religious reasons. In some situations methods such as external features and less expensive methods such as finger printings and dental findings could be used for identification. Therefore in Sri Lanka, DNA is being used in specific circumstances where an additional evidentiary value is needed.

\section{Introduction}

DNA is one of the most reliable methods of identification. But there are disadvantages such as high cost, and necessity of comparative 
cases or when there is a necessity to prove identity beyond reasonable doubt in the court of law.

\section{Case report}

Several people died following a blast in or around an armory of a police station during the terrorism period in Sri Lanka. During the scene visit it was noticed that it was difficult to protect the scene from public invasion even with cordoning.

The bodies were searched for about $650-700 \mathrm{~m}$ away from the locus of the blast and one body was recovered $650 \mathrm{~m}$ away. All the bodies of the missing persons but the bodies of the two police officers who were on duty near the armory were recovered. After the initial scene investigation, 23 bodies were dispatched to the nearest tertiary care hospital (Figure 1) along with two bags with parts of bodies. These bags contained body parts recovered $150 \mathrm{~m}$ away from each other.

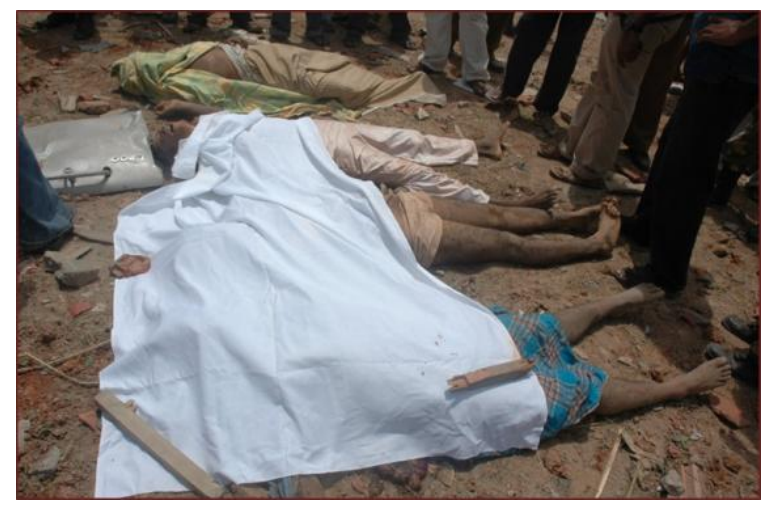

Figure 1. Identifiable bodies were dispatched.

Those 23 complete bodies were recognized by facial features. The other two bodies recovered as body parts in the two bags were differentiated by using following features. According to the history, one officer had been bald headed, dark in complexion and had hair on his ears. The other one had been young and fair in complexion.

At the autopsy, in one bag, there were parts of scalp that showed baldness and hair on the ears. (Figure 2) and parts from an index finger (Figure 3). Fingerprints were used to confirm the identification.

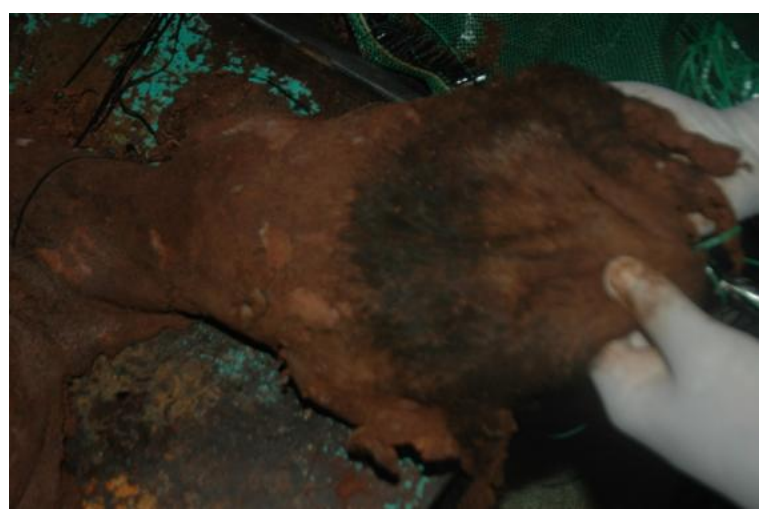

Figure 2. Baldness of the head

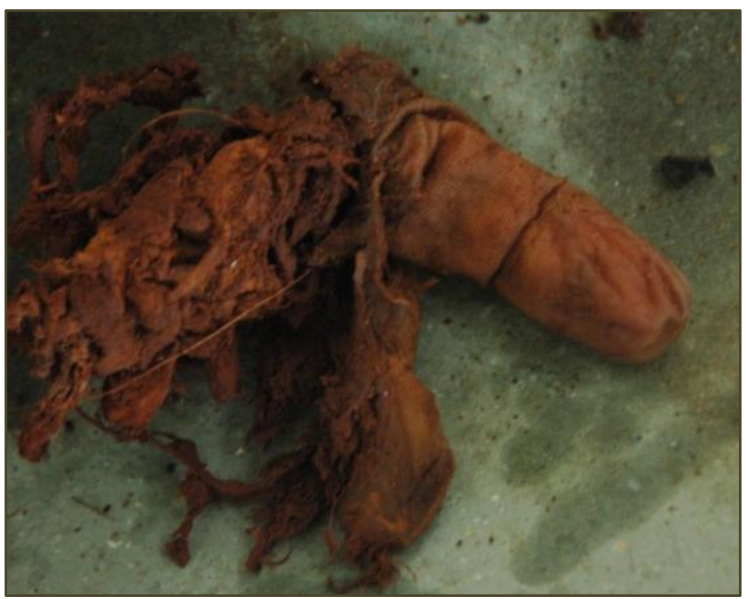

Figure 3. An index finger found in the first bag

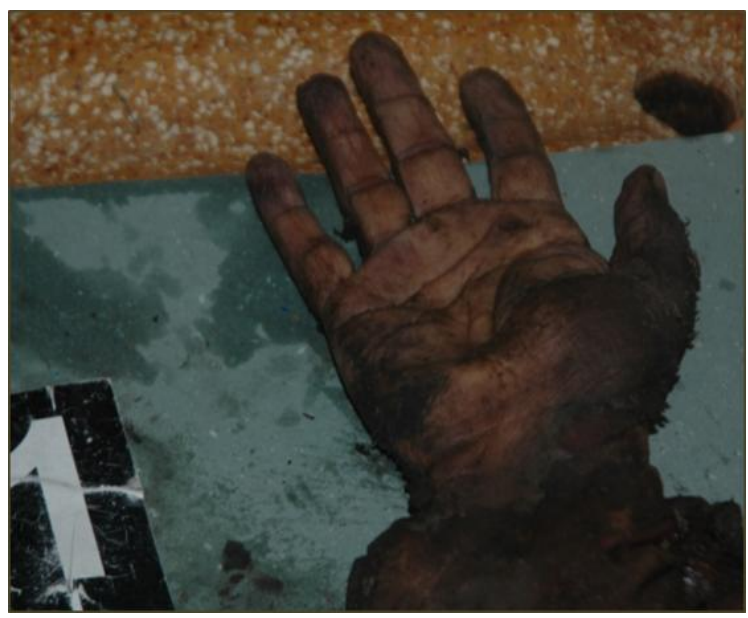

Figure 4. The Hand found in the second bag 
In the second bag, there were pieces of a camouflage T-shirt and a full hand (Figure: 4). Fingerprints were used in this case also to confirm the identity. Later, DNA testing reconfirmed the identifications.

\section{Discussion}

The forensic pathologist has always had a central role in the identification of mass disasters. This role has changed in recent years, as advances in forensic odontology, anthropology and genetics have improved the chances of identifying victims beyond recognition. According to the Interpol Disaster victim identification (DVI) guide, fingerprints, dental examination and DNA are the primary identifiers, and this has given new emphasis to the role of the forensic pathologist as the leader of the multidisciplinary team in a disaster situation [1]. The role of other agencies including the Red Cross (ICRC) in DVI operations play a critical supporting role and provide an unquestioned service to survivors and families of those who are killed [2].

Mass disasters result in loss of many lives and property [3]. Law enforcement and forensic experts often have the responsibility of identifying the human remains found at the scene, so those can be handed over to their families. The recovered human remains range from being relatively intact to a highly degraded state and DNA-based identity testing is a powerful tool for identification of those victims [4]. Therefore the forensic or dental expert, or the forensic scientist has to collect samples for DNA analysis.

General guidelines are provided for identification of human remains from a mass disaster by DNA analysis. These include: 1) sample collection, preservation, storage and dispatch; 2) chain of custody; 3) laboratory facilities; 4) quality assurance and quality control; 5) parsing out work; 6) extraction and typing; 7) interpretation of results; 8) automation; 9) software for tracking and managing data; 10) the use of an advisory panel; 11) education and communication; and 12) privacy issues [4]. In addition, key DNA technologies that may facilitate the identification process include: resin based DNA extraction, PCR for quantification of DNA, miniSTRs, SNP detection procedures, and soft wares [4]. Therefore, developing a missing persons DNA identification program or a mass disaster human remains DNA identification program should be done methodically. The Government analyst Department of Sri Lanka has established a well-equipped DNA centre in February 2013. Since it is of high cost, currently DNA profiling is being used only when it is necessary to prove the identity beyond reasonable doubt in a court of law.

In this investigation, non-usage of the INTERPOL DVI protocol for the identification of deaths was a drawback. According to the protocol for DVI operations established on 7th January 2005, the first principle is that every victim would be treated equally without prejudice and the second principle is that the INTERPOL DVI process would be the agreed method to deliver the identity of all victims [2]. Therefore, ideally in a mass disaster, bodies should not be released until the investigations are completed. But in Sri Lanka, the relatives and friends as well as politicians are keen to get the bodies released as early as possible. Religious customs like disposal within 24 hours of death should be respected by the forensic investigators as far as possible. The 23 bodies which were recognized using facial features were released soon due to such religious reasons.

Body parts found in the two body bags were the most important in the investigation of blasts because those victims could have either been touching the explosives or in the near vicinity and therefore would have led to disintegration into body parts. Therefore, the Identification process of the smaller body parts should be done meticulously. In some situations methods such as external features and less expensive methods such as fingerprinting or dental findings could be used for identification. In this instance, fingerprints were used for initial confirmation but dental data were not available 
among the pieces for re-confirmation. Therefore, the two identifications were reconfirmed by DNA profiling.

Further, for the bodies with mutilation or medico-legal significance, additional caution must be taken to overcome the involvement of a terrorist or an intruder. In such instances, the correct identification is important to answer the subsequent legal issues. Therefore in Sri Lanka, in addition to these quick and feasible identification techniques such as fingerprints or dental identification [5], DNA is being used selectively, in specific circumstances where an additional evidentiary value is needed.

\section{References}

1. Schuliar Y, Knudsen PJ.Role of forensic pathologists in mass disasters. Forensic Sci Med Pathol. 2012 Jun;8(2):164-73.

2. INTERPOL Tsunami Evaluation Working Group. The DVI Response to the South East Asian Tsunami between December 2004 and February,2006. www.cmu.edu/chrs/conferences/eppi/docs/ Tsunami-Evaluation2010.pdf. (accessed on 12.01.2015)

3. Landesman YL. Public health management of disasters: The practice guide. American Public Health Association, NW, Washington, 2001.

4. Budowlea B, Bieberb FR, Eisenbergc AJ, Forensic aspects of mass disasters: Strategic considerations for DNA-based human identification, Legal Medicine 7 (2005) 230243

5. Nuzzolese E, Missing people, migrants, identification and human rights. J Forensic Odontostomatol. 2012 Nov 30; 30Suppl 1:47-59.

\section{Contribution of authors}

Performing the autopsy- MMAR, KMTBG

Opinion- KMTBG

Writing the manuscript -MV, KMTBG

Revising the manuscript- MV, KMTBG 